\title{
EVALUATION OF THE EFFECTIVENESS AND SAFETY OF REMSIMA (INFLIXIMAB BIOSIMILAR) IN COMPARISON WITH THE REMICADE, IN PATIENTS WITH TAKAYASU'S ARTERITIS
}

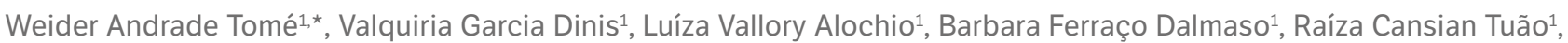
Letícia Fonseca Favarato ${ }^{1}$, Thaís Chaves Belisário1, Priscila Costa Martins Rocha ${ }^{1}$, Thaís Segato Garcia ${ }^{1}$, Bárbara Petronetto Fafá Fardin ${ }^{1}$, Ketty Lysie Libardi Lira Machadoํㅜㄹ Ruben Horst Duque ${ }^{1}$, Valéria Valim ${ }^{1}$

1.Universidade Federal do Espírito Santo, Vitória (ES), Brazil.

${ }^{*}$ Corresponding author: weidertome@hotmail.com

\section{BACKGROUND}

Biosimilars have been new therapeutic options for immune-mediated diseases, mainly because they have a better pharmacoeconomic profile. Remsima is an infliximab biosimilar approved by the European Medicines Agency Committee in September 2013 and by the US Food Drug Administration in April 2016 for all originator product indications. In Brazil, its use has been released in 2017, and is use was imposed in the Public Health System (SUS) in the state of Espírito Santo, in place of Remicade for the indications Takayasu's arteritis, sarcoidosis, Behçet's disease and uveitis in 2019.

\section{METHODS}

The study population consists of patients over 18 years of age with Takayasu's arteritis according to the criteria of the American College of Rheumatology (ACR) 1990 and outpatient medical follow-up at the vasculitis outpatient clinic of University Hospital of Federal University of Espírito Santo (HUCAM-UFES/EBSERH).

\section{RESULTS}

Infliximab was the most used biological agent in this group of patients, being used by 6 patients (40\%). No adverse reactions were described during its period of use; however, 5 (83.3\%) changed the medication to its biosimilar Remsima due to economic reasons, by government decision and patient (16\%) had therapeutic failure. Of all 5 using Remsima, 1 patient (20\%) had an adverse reaction with skin rash and pruritus, and 2 patients (40\%) had treatment failure. When performed, the comparative analysis of patients who automatically switched from infliximab to Remsima, it was observed that with Remsima, patients had more adverse events ( $20 \%$ vs. $0 \%, p<0.0001)$ and more treatment failure ( $40 \%$ vs. $16 \%, p<0.0001)$. Of the 5 patients who were using Remsima, $3(60 \%)$ had to discontinue the medication for these two reasons above. It was also observed that the average usage time for Remsima was almost 4 times lower than for infliximab ( $8 \pm 6.59$ vs. $33 \pm 23.24$ months, $p=0.0338)$.

\section{CONCLUSION}

Automatic switching of biological treatment was not beneficial and was linked to more adverse events, therapeutic failures, and shorter drug use.

\section{KEYWORDS}

Remsima, Infliximab, Biosimilar. 